\title{
Revitalisasi Amaliah Nahdlatul Ulama (NU) dalam Menangkal Faham Radikalisme di Madrasah Aliyah
}

\author{
Zulfa Fiqria $^{1}$, Zaenal Arifin ${ }^{2}$ \\ 1,2Institut Agama Islam Tribakti (IAIT) Kediri \\ ${ }^{1}$ fiqriazulfa20@gmail.com, ${ }^{2}$ zae.may13@gmail.com
}

\begin{abstract}
The spread of radicalism in education requires students to fortify and strengthen their beliefs to not fall into radicalism. The researcher aims to discover the revitalization of NU's practice in countering radicalism in schools. In this study, the type of field research is descriptive analysis. This study resulted in research findings, namely the implementation of NU's Islamic tradition in the form of grave pilgrimage of Walisanga and Asmaul Husna reading, as well as a form of revitalization in countering radicalism through NU's Islamic tradition practice for strengthening Aswaja's theology.
\end{abstract}

Keywords: Islamic Tradition, Nahdlatul Ulama, Radicalism

\begin{abstract}
Abstrak
Seiring bersebarnya faham radikalisme di kalangan pendidikan, mengharuskan siswa membentengi dan memperkuat akidah agar tidak terjerumus dalam faham radikalisme. Tujuan peneliti yakni mengetahui revitalisasi amaliah NU dalam menangkal radikalisme di kalangan sekolah. Dalam penelitian ini menggunakan jenis penelitian kualitatif yang bersifat deskriptif analisis. Penelitian ini menghasilkan temuan penelitian yakni pelaksanaan amaliah NU berupa ziarah Walisanga dan pembacaan Asmaul Husna, serta bentuk revitalisasi dalam menangkal faham radikalisme melalui pembiasaan amaliah NU sehingga dapat menguatkan akidah Aswaja.
\end{abstract}

Kata Kunci: Nahdlatul Ulama, Radikalisme, Tradisi Islam

\section{Pendahuluan}

Indonesia merupakan negara yang mempunyai keanekaragaman sosial, budaya, dan agama. Semua ini bisa dilihat dari letak geografis, sosiokultur, suku, dan agama yang sangat beragam. Namun belakangan ini, Indonesia digemparkan oleh adanya paham radikalisme yang bermula dari adanya modernisasi dan kemerosotan akhlak. Agama menjadi sebuah solusi mengenai kemerosotan akhlak, namun sebaliknya, agama menjadi sumber masalah 


\section{Revitalisasi Amaliah Nahdlatul Ulama..., Zulfa Fiqria, Zaenal Arifin}

bagi pengikutnya yang menganggap agamanya yang paling benar. ${ }^{1}$ Bahaya radikalisme semakin meluas di semua kalangan, terlebih di lingkungan sekolah. Seperti yang dikatakan oleh Mustiqowati Ummul Fithriyah dan M. Saiful Umam bahwa menanggulangi radikalisme bukan suatu hal yang mudah dilakukan, hal tersebut dikarenakan dalam radikalisme bukan hanya menggemborkan gerakan sosial, namun mereka juga memengaruhi ideologi seseorang. Tindakan yang perlu dilakukan yakni dengan menerapkan Pendidikan Aswaja yang menanamkan karakter atau nilai Aswaja sehingga dapat menangkal faham radikalisme di sekolah. ${ }^{2}$ Sedangkan dalam penelitian ini, tindakan yang dilakukan dalam menangkal faham radikalisme dengan melalui pembiasaan penerapan amaliah Nahdlatul Ulama di lingkungan sekolah.

Pendapat tersebut dikuatkan Irwan Masduqi bahwa Islam yang terkenal sebagai agama kedamaian dengan mengajarkan umatnya untuk selalu berdamai menjadi tercoreng dengan adanya kelompok radikal yang menyebarkan fahamnya melalui kekerasan. Untuk menanggulangi radikalisme tersebut, perlu adanya implementasi prinsip pendidikam Islam berbasis multikulturalisme guna meningkatkan kesadaran saling menghargai, sebab saat ini Indonesia belum bersih dari ancaman radikalisme. Tujuan pendidikan Islam tidak lain yakni membentuk karakter peserta didik agar memiliki sikap simpati, menghormati, mengapresiai dan empati terhadap orang lain. Dengan sikap-sikap tersebut, diharapkan bisa menanggulangi paham radikalisme yang mengajarkan fahamnya dengan kekerasan. ${ }^{3}$

Selain itu, Mukodi mengatakan bahwa dalam menyebarkan alirannya, radikalisme telah memengaruhi kehidupan umat Islam termasuk dunia pesantren. Hal ini perlu segera diantisipasi karena pesantren merupakan lembaga pendidikan tertua di Indonesia yang di dalamnya menanamkan pendidikan dan nilai-nilai pesantren. Dengan begitu perlu adanya pendidikan nasionalisme yang diajarkan di dunia pesantren. Pendidikan nasionalisme tersebut bisa dilakukan dengan cara menanamkan paham nasionalisme melalui pembelajaran sehari-hari. ${ }^{4}$ Seseorang yang mempunyai ideologi NU kuat dan hidup di kalangan NU atau pondok pesantren yang berbasis NU tidak akan terpengaruh dalam faham radikalisme. Namun tidak bisa dimungkiri, bahwa di antara orang yang berada di kalangan tersebut bisa

\footnotetext{
${ }^{1}$ Sultoni, Maskuri, dan Fita Mustafida, "Peran Guru Pendidikan Agama Islam dalam Menanamkan Amaliyah Ahlussunah wal Jama'ah Siswa di SMP Nahdhatul Ulama Pakis Malang," Vicratina: Jurnal Pendidikan Islam, Vol. 6, No. 1, (2021), 55.

${ }^{2}$ Mustiqowati Ummul Fithriyah dan M. Saiful Umam, "Internalisasi Nilai-Nilai Aswaja dalam Pendidikan Islam sebagai Upaya Deradikalisasi Menuju Good Citizen," Seminar Nasional Islam Moderat, 2018, 115.

${ }^{3}$ Irwan Masduqi, "Deradikalisasi Pendidikan Islam Berbasis Khazanah Pesantren," Jurnal Pendidikan Islam, Vol. 2, No. 1, (2013), 9.

${ }^{4}$ Mukodi Mukodi, "Kurikulum dan Pendidikan Nasionalisme di Pondok Pesantren Tremas," Al Izzah: Jurnal Hasil Penelitian, Vol. 15, No. 1, (2020), 15.
} 
terjerumus dalam faham radikalisme. Dengan begitu, peran guru di lingkungan sekolah pun juga penting untuk menghidupkan kembali cara untuk menangkal faham radikalisme. Salah satu di antaranya yakni sebagaimana dalam penelitian ini, yakni amaliah NU yang diterapkan di Madrasah Aliyah Al-Mahrusiyah Lirboyo Kediri (MAAMLK) guna menguatkan akidah Aswaja sehingga tidak mudah terjerumus dalam faham radikalisme.

Meskipun demikian, Candra Syahputra mengungkapkan santri yang mempunyai keunggulan ilmu teknologi, diharapkan bisa berdakwah melalui media sosial. Dengan begitu, santri bisa berdakwah tentang ilmu yang telah dimiliki melalui media sosial untuk memperkuat akidah dan tidak terjerumus ke dalam faham radikalisme. ${ }^{5}$ Selain itu, Ahmad Yani mengungkap bahwa bahaya radikalisme bisa terjadi sejak dini. Sehingga cara menangkal masuknya radikalisme juga harus dilaksanakan sejak dini di lingkungan sekolah. Target yang dilakukan dalam pencegahan radikalisme tersebut yakni melalui pemilihan buku ajar yang tepat, menyeleksi calon guru, dan kerja sama antara guru dengan wali murid mengenai parenting. ${ }^{6}$ Hal tersebut juga dikatakan oleh Amir dkk bahwa menangkal faham radikal dilakukan melalui penguatan akidah (indoktrinasi) tentang faham Aswaja kepada peserta didik. Upaya indoktrinasi tersebut dilakukan dengan metode pembiasaan, kisah, dan keteladanan. Selain itu, upaya untuk menangkal faham radikalisme bagi siswa yakni dengan adanya penguatan muatan lokal Aswaja An-Nahdliyah. ${ }^{7}$

Dengan demikian, penelitian ini mengungkapkan amaliah NU yang diterapkan oleh MAAMLK sebagai bentuk penguatan akidah Aswaja dan menanggulangi faham radikalisme di lingkungan sekolah. MAAMLK adalah sekolah formal yang berada di bawah naungan Pondok Pesantren HM Al-Mahrusiyah Lirboyo Kota Kediri. ${ }^{8}$ Dalam kesehariannya, kegiatan di MAAMLK mengikuti program yang ada di Pondok Pesantren Al-Mahrusiyah. Program kegiatan yang dilakukan di MAAMLK tidak jauh dari amaliah-amaliah NU, karena pondok pesantren Al-Mahrusiyah sendiri berpaham Ahlussunnah Wal Jama'ah yang selalu mengaitkan kegiatan amaliah-amaliah Nahdlatul Ulama (NU) yang ditujukan untuk menguatkan akidah santri tentang ke-NU-an dan agar tidak terjerumus kepada faham radikalisme.

\footnotetext{
${ }^{5}$ Muhammad Candra Syahputra, "Jihad Santri Mellenial Melawan Radikalisme di Era Digital: Studi Gerakan Arus Informasi Santri Nusantara di Media Sosial,” Jurnal Islam Nusantara, Vol. 04, No. 01, (2021), 75.

6 Ahmad Yani dan Jazariyah, "Penyelenggaraan PAUD Berbasis Karakter Kebhinekaan sebagai Upaya Pencegahan Radikalisme Sejak Dini," Jurnal Obsesi: Jurnal Pendidikan Anak Usia Dini, Vol. 5, No. 1, (2021), 5.

7 Amir, Hasan Baharun, dan Lina Nur Aini, "Penguatan Pendidikan Aswaja An-Nahdliyah untuk Memperkokoh Sikap Toleransi," Jurnal Islam Nusantara, Vol. 04, No. 02, (2020), 194.

${ }^{8}$ Imam Washoli, Sejarah MA Al-Mahrusiyah Lirboyo Kota Kediri, Wawancara, June 15, 2021.
} 


\section{Metode}

Penelitian ini menggunakan jenis penelitian kualitatif dengan pendekatan fenomenologi. ${ }^{9}$ Kajian fenomenologi dalam penelitian ini digunakan untuk memahami bagaimana pengalaman informan mengenai revitalisasi amaliah NU dalam menangkal faham radikalisme di MAAMLK sehingga ditemukan struktur inti di balik pengalaman informan terhadap suatu fenomena. Teknik pengumpulan data dalam penelitian ini menggunakan wawancara mendalam terhadap informan berupa guru Aswaja, Waka Kesiswaan, Pembina IPNU-IPPNU, panitia ziarah walisanga, dan beberapa siswa MAAMLK. Sumber data yang peneliti gunakan yakni melalui wawancara, dokumentasi, dan observasi. Teknik analisis data menggunakan model alur melalui tahap reduksi data, penyajian data, dan penarikan kesimpulan. ${ }^{10}$ Penyajian data yang dilakukan peneliti yakni dengan : (a) Reduksi data, peneliti pemilihan data yang diperoleh pada saat penelitian mengenai pelaksanaan amaliah NU MAAMLK. Dari data tersebut peneliti membagi kegiatan amaliah NU yang dilakukan MAAMLK, yakni ziarah walisanga dan pembacaan Asmaul H\}usna. (b) Penyajian data, peneliti mendeskripsikan data yang diperoleh dari informan dengan kalimat berbentuk simpulan dan disajikan dalam bentuk teks naratif. Sajian data ini menggunakan kalimat yang logis dan sistematis sehingga memudahkan pembaca dalam memahami sesuai dengan penelitian. Peneliti melakukan penyajian data tentang amaliah NU yang dilakukan MAAMLK dalam menangkal faham radikalisme. (c) Penarikan kesimpulan, peneliti menyimpulkan seluruh data yang pernah disimpulkan sebelumnya. Pengecekan keabsahan data yang dilakukan peneliti menggunakan triangulasi. Peneliti mengecek semua sumber dengan berbagai cara dan waktu, di antaranya peneliti membandingkan informasi yang diperoleh dari setiap informan atau sumber, serta melakukan wawancara untuk memperoleh informasi tentang amaliah NU yang dilakukan di MAAMLK.

\section{Pembahasan}

\section{Bentuk Pelaksanaan Amaliah NU}

MA Al-Mahrusiyah Lirboyo Kediri (MAAMLK) merupakan lembaga pendidikan formal yang berada di bawah naungan pondok pesantren yang berpaham Ahlussunnah wal Jama'ah. Dalam kesehariannya, berbagai amaliah-amaliah NU diterapkan di pondok

\footnotetext{
${ }^{9}$ Sugiyono, Metode Penelitian Kuantitatif, Kualitatif, dan R\&D (Bandung: Alfabeta, 2012), 253.

${ }^{10}$ Hardani dkk, Metode Penelitian Kuantitatif \& Kualitatif, 1st ed. (Yogyakarta: CV. Pustaka Ilmu Group Yogyakarat, n.d.), 163.
} 
pesantren dan juga di Madrasah Aliyah. Tujuan dari penerapan amaliah NU tersebut yakni sebagai pembiasaan kepada siswa-siswi supaya mengenal dan terbiasa mengamalkan amaliah NU sejak dini. Dalam penelitian ini, peneliti menemukan beberapa amaliah NU yang diterapkan di MAAMLK.

a. Ziarah Walisanga

Ziarah Walisanga merupakan berkunjung ke makam para wali dengan tujuan untuk mendo'akan dan mengharapkan barokah (berkah) dari wali tersebut. ${ }^{11}$ Kegiatan ziarah ditujukan untuk mengenalkan makam Walisanga kepada siswa dan juga mengajarkan siswa untuk membiasakan diri mengamalkan amaliah NU berupa ziarah kubur, serta untuk memperkuat faham Aswaja siswa melalui amaliah NU yakni ziarah Walisanga. Menanamkan nilai-nilai karakter Aswaja merupakan bentuk dari deradikalisme. Nilai-nilai tersebut adalah tawasut\}, tawazun, tasamuh, dan i'tidal. Selain itu, membiasakan peserta didik melalui amaliah Aswaja juga sangat berpengaruh dalam menguatkan akidah Aswaja. Di antaranya yakni istighatsah, diba'an, tahlilan, ziarah kubur, dan peringatan hari besar Islam. ${ }^{12}$ Ziarah Walisanga yang diadakan MAAMLK merupakan suatu kegiatan yang bisa menangkal faham radikalisme di kalangan pelajar, terlebih untuk siswa SMA yang pola pemikirannya masih mudah terpengaruh. ${ }^{13}$ Mengingat faham radikalisme dalam penyebarnnya sangat keras dan fanatik, maka tidak heran jika yang menjadi sasaran mereka adalah kaum remaja.

Dalam kamus besar Bahasa Indonesia (KBBI) ziarah diartikan sebgai berkunjung ke tempat yang dianggap mistis atau mulia (makam dan sebagainya). ${ }^{14}$ Ziarah merupakan salah satu rutinitas umat Islam yang sudah melekat dalam budaya masyarakat Indonesia. Sejarah mengatakan konsep ziarah ini terjadi karena kepercayaan umat Islam terhadap karamah pada diri Wali yang mana mampu memecahkan persoalan yang dihadapi oleh seseorang. Meskipun Wali sudah meninggal, mereka percaya bahwa karamah yang dimiliki Wali tersebut masih ada. Akhirnya mereka berupaya dengan cara berziarah ke makam tempat

\footnotetext{
${ }^{11}$ Hikmatul Mustaghfiroh dan Muhammad Mustaqim, “Analisis Spiritualitas Para Pencari Berkah (Studi Atas Motivasi Penziarah di Makam Sunan Kalijaga Kadilangu Demak),” Jurnal Penelitian, Vol. 8, No. 1 (2014), 144.

12 Ummul Fithriyah and Saiful Umam, "Internalisasi Nilai-Nilai Aswaja dalam Pendidikan Islam Sebagai Upaya Deradikalisasi Menuju Good Citizen," 121.

13 Abdul Haris Masyrufi dan Oksiana Jatiningsih, "Partisipasi Remaja Masjid dalam Mencegah Penyebaran Radikalisme Islam di Desa Mojopurogede Kecamatan Bungah Kabupaten Gresik," Kajian Moral dan Kewarganegaraan, Vol.5, No. 1, (2017), 510.

14 Kemdikbud, "Kamus Besar Bahasa Indonesia (Kbbi) Daring," 2021, Https://Kbbi.Kemdikbud.Go.Id/Entri/Radikalisme.
} 
Wali disemayamkan. ${ }^{15}$ Selain itu, ziarah Walisanga juga sebagai wujud pencarian barokah melalui perantara ziarah kepada 'alim-'ulama dan para wali. Sejarahnya, ziarah kubur dilakukan oleh orang muslim zaman dahulu yang masih dilestarikan sampai saat ini oleh Islam beraliran nahdliyin (NU) yang meyakini tentang wasilah atau perantara orang-orang suci. Ketika berziarah mereka berkeyakinan bahwa ketika berdo'a kepada Allah melalui perantara orang suci maka do'a nya akan cepat terkabul. Hal tersebut dikarenakan mereka beranggapan bahwa seorang yang suci itu memiliki hubungan yang kuat terhadap Allah SWT. Orang-orang suci tersebut yakni seperti Rasulullah, kerabat Nabi Muhammad, dan Waliyullah. ${ }^{16}$

Menurut data yang diperoleh peneliti, MAAMLK mempunyai beberapa tujuan makam dalam kegiatan ziarah Walisanga. Mulai dari Jawa Timur sampai Jawa Barat. Dalam agenda tersebut, selain mengunjungi makam sembilan wali, MAAMLK juga mengunjungi beberapa makam ulama-ulama yang berada di tanah Jawa. Di pulau Jawa, terdapat beberapa wali yang sangat berperan dalam penyebaran dakwah Islam. Para wali ini dikenal dengan sebutan Walisanga atau Wali Sembilan. Penyebutan Sembilan dikarenakan wali tersebut berjumlah sembilan orang. Masyarakat Jawa menjadikan ziarah Walisanga sebagai bentuk rutinitas penting yang mendapatkan apresiasi tinggi di masyarakat Islam. Karena dengan ziarah Walisanga, masyarakat biasanya mengharapkan wasilah atau ngalap barokah kepada wali. $^{17}$

Dalam berziarah Walisanga, MAAMLK mengagendakan dengan membacakan tahlil di setiap makam yang dituju. Sebelum membaca tahlil, diawali terlebih dahulu dengan membaca salam kepada ahli kubur dan juga membacakan tawasul. Selain tahlil, biasanya di makam-makam tertentu ditambah dengan bacaan istighatsah bersama. Pembacaan mulai dari tawasul, tahlil, dan istighatsah dipimpin langsung oleh perwakilan zuriyyah (keluarga pengasuh pesantren). Tahlil merupakan berdo'a bersama dengan kalimah tayyibah dengan tujuan untuk mendo'akan orang yang telah meninggal. ${ }^{18}$ Di Indonesia khususnya, dalam perkembangannya, tahlil ditambahkan sebagai ritual keagamaan yang memuat susunan rujukan dari sebagian ayat-ayat Al-Qur'an. ${ }^{19}$

\footnotetext{
${ }^{15}$ Hikmatul Mustaghfiroh dan Muhammad Mustaqim, “Analisis Spiritualitas Para Pencari Berkah (Studi Atas Motivasi Penziarah di Makam Sunan Kalijaga Kadilangu Demak),” Jurnal Penelitian, Vol. 8, No. 1, (2014), 144.

${ }^{16}$ Rosada dan Wawansyah, "Tradisi Ziarah Kubur Masyarakat Sasak (Studi Kasus Makam Loang Baloq)," Jurnal Historis, Vol. 2, No. 1, (2017), 32.

${ }^{17}$ Mustaghfiroh and Mustaqim, 145.

18 Andi Warisno, "Tradisi Tahlilan Upaya Menyambung Silaturahmi," Ri'ayah, Vol. 2, No. 2, (2017), 71.

${ }^{19}$ Fatimatuz Zahra, "Tradisi Aswaja Dalam Prespektif Filsafat Terapan," Seminar Nasional Islam Moderat, $2018,45$.
} 


\section{Revitalisasi Amaliah Nahdlatul Ulama..., Zulfa Fiqria, Zaenal Arifin}

b. Pembacaan Asmaul Husna

Asmaul Husna merupakan nama-nama Allah yang indah dan baik. Pembiasaan melafalkan Asmaul Husna merupakan anjuran dari Allah SWT dan Rasul-Nya. MAAMLK membiasakan membaca Asmaul Husna setiap harinya. Kegiatan tersebut dilakukan pada pagi hari sebelum jam pelajaran dimulai. Pembacaan Asmaul Husna wajib diikuti oleh seluruh siswa siswi MAAMLK. Kegiatan tersebut bertujuan untuk membiasakan seluruh siswa untuk membaca wirid Asmaul Husna dalam kesehariannya dan sebagai bentuk pelaksanaan dari perintah KH. Imam Yahya untuk membaca Asmaul Husna setiap hari.

Asmaul Husna merupakan salah satu ilmu pengetahuan yang berkaitan dengan ilmuilmu keislaman. Dengan mempelajari Asmaul Husna, kita dapat mengetahui nama-nama yang baik, agung, dan indah sesuai dengan sifat-sifat-Nya. ${ }^{20}$ Kebiasaan membaca Asmaul Husna memungkinkan berhubungan dengan kecerdasan emosional. Seseorang yang setiap harinya membaca Asmaul Husna memungkinkan berpengaruh terhadap pengalaman batinnya. Bentuk pengalaman batin ini seperti mempunyai ketenangan hati, memiliki rasa syukur, sabar, dan ikhlas. Dengan memperoleh ketenangan hati tersebut memungkinkan seseorang untuk dapat mengendalikan dirinya, dan mempunyai sudut pandang kecerdasan emosional, sehingga dapat membentengi dirinya dari hal-hal yang membuat seseorang terpengaruh ke dalam aliran yang salah ${ }^{21}$

\section{Amaliah NU dalam Menangkal Faham Radikalisme}

Penerapan ziarah Walisanga dan pembacaaan Asmaul Husna di MAAMLK merupakan kegiatan yang diupayakan untuk menguatkan pemahaman siswa tentang Aswaja melalui bentuk amaliah NU. Kegiatan tersebut dilakukan mengingat pengetahuan siswa mengenai Aswaja hanya diperoleh melalui teori saja, yakni pembelajaran Aswaja ke-NUan. Akhir-akhir ini faham radikalisme juga beredar di kalangan pelajar. Dengan demikian MAAMLK melakukan cara yang dapat memperkuat paham Aswaja ke-NU-an siswa melalui penerapan amaliah-amaliah NU di lingkungan madrasah. Ideologi Islam Nahdliyin (Aswaja) harus dikuatkan kembali dan disebarkan melalui berbagai media dan sarana. Salah satunya yakni dilakukan dengan cara menerapkan amaliah Aswaja yang menanamkan nilai

\footnotetext{
${ }^{20}$ Sri Ariyati dan Titik Misriati, "Perencanaan Animasi Interaktif Pembelajaran Asmaul Husna,” Jurnal Teknik Komputer Amik BSI, Vol. 2, No. 1, (2016), 116.

${ }^{21}$ Lili Khoirunnisa, "Hubungan Antara Kebiasaan Membaca Asmaul Husna dengan Kecerdasan Emosional Siswa Kelas XI MA Nurul Ummah Yogyakarta,” Jurnal Pendidikan Agama Islam, Vol. 14, No. 1, (2017), 60.
} 


\section{Revitalisasi Amaliah Nahdlatul Ulama..., Zulfa Fiqria, Zaenal Arifin}

pendidikan di dalamnya. Hal tersebut dikarenakan pendidikan merupakan salah satu tempat lembaga yang tepat untuk menangkal faham radikalisme sejak dini. ${ }^{22}$

a. Ziarah Walisanga

Ziarah Walisanga merupakan suatu kegiatan amaliah NU MAAMLK untuk menangkal faham radikalisme. Melalui ziarah Walisanga, siswa akan mengetahui dan mempraktikkan amaliah NU yang berpaham Aswaja. Mengingat semakin maraknya radikalisme di berbagai kalangan, kegiatan ziarah diharapkan bisa membentengi siswa dari aliran tersebut. Karena dengan berziarah Walisanga, siswa akan mengetahui bahwa Aswaja adalah suatu paham yang tidak menggunakan kekerasan dan penuh dengan kedamaian. Hal ini dikarenakan agama Islam dikenal sebagai agama yang mengajarkan umatnya untuk selalu berdamai. $^{23}$

Sebelum membahas tentang menangkal radikal melalui ziarah Walisanga, peneliti akan membahas tentang radikalisme terlebih dahulu. Radikalisme merupakan suatu faham aliran yang memengaruhi masyarakat secara besar-besaran dengan menggantikan nilai-nilai yang ada secara drastis melalui tindak kekerasan dan aksi yang ekstrem. Radikalisme merupakan suatu aliran yang menyebarkan ideologinya dengan cara pemaksaan dan kekerasan. Di samping itu, agama Islam tidak pernah membenarkan tindakan kekerasan atau pemaksaan dalam menyebarkan agamanya, karena agama Islam sendiri adalah agama yang mengedepankan kedamaian dalam segala bentuk amaliahnya. ${ }^{24}$

Penerapan amaliah NU di setiap lembaga pendidikan diharapkan akan tertanam nilainilai Aswaja dalam diri seseorang yang pada gilirannya akan menangkal ideologi radikal. Selain untuk membentengi dari faham radikalisme, penerapan amaliah NU juga sebagai bentuk memelihara tradisi keagamaan ala Aswaja yang telah diajarkan secara turun temurun oleh para ulama terdahulu. ${ }^{25}$ Dengan begitu, MAAMLK selain menerapkan pelajaran keNU-an, juga menerapkan beberapa amaliah NU. Ziarah sendiri merupakan berkunjung ke makam seseorang yang sudah meninggal. Biasanya, ziarah dilakukan ke makam-makam para ulama dan wali. Ziarah kubur menjadi suatu pembiasaan amaliah NU yang bisa

\footnotetext{
${ }^{22}$ Ahmad Fauzi, "Jam'iyah Yasin sebagai Media Penyebaran Islam Moderat pada Masyarakat," Proceeding: The 1st Faqih Asy'ari Islamic Institute International Conference Faqih Asy'ari Islamic Institute Sumbersari Kediri, Indonesia, Vol. 2, (2019), 107.

${ }^{23}$ Irwan Masduqi, "Deradikalisasi Pendidikan Islam Berbasis Khazanah Pesantren," Jurnal Pendidikan Islam, Vol. 2, No. 1, (2013), 9.

${ }^{24}$ A Faiz Yunus, "Radikalisme, Liberalisme, dan Terorisme: Pengaruhnya Terhadap Agama Islam," Jurnal Studi Al-Qur'an, Vol. 13, No. 1, (2017), 80.

${ }^{25}$ Fathur Rohman dan Hanifa A'la, "Pembiasaan Tradisi Aswaja sebagai Upaya Pencegahan Radikalisme di Madrasah Aliyah Matholi’ul Huda Kedung Jepara," El-Banat Jurnal Pendidikan Islam, Vol. 10, No. 1, (2020), 39.
} 
memperkuat faham Aswaja. Karena dengan berziarah kita akan mengikuti tradisi yang dilakukan oleh Nabi Muhammad SAW. Selain itu kita dapat mengirimkan do'a kepada orang yang sudah meninggal agar ditempatkan dengan nyaman di sisi Allah, dan kita juga dapat mengingat akan kematian. ${ }^{26}$

b. Pembacaan Asmaul Husna

Pembacaan Asmaul Husna merupakan kegiatan harian yang dilaksanakan MAAMLK untuk membentengi siswa dari faham radikalisme. Dengan pembiasaan membaca Asmaul Husna diharapkan siswa mempunyai ketenangan hati dan pikiran sehingga tidak mudah terjerumus ke dalam faham radikalisme yang terkenal kolot. Menangkal faham radikalisme perlu dilakukan sejak dini dan di lingkungan sekolah atau madrasah. Hal ini dikarenakan radikalisme menyebarkan alirannya tidak hanya melalui kekerasan dan penghasutan saja, melainkan dapat dilakukan dengan cara lemah lembut melalui iming-iming terhadap usia remaja yang pola pikirnya masih labil. Untuk menangkal hal tersebut, di lingkungan sekolah perlu diadakan pembiasaan kegiatan amaliah NU yang berada di luar jam pembelajaran. Seperti salat duha berjama'ah, membaca Asmaul Husna, mengikuti kasidah hadrah, dan lain sebagainya. ${ }^{27}$ Pembiasaan harian dengan pembacaan Asmaul Husna di MAAMLK menjadi salah satu bentuk penguatan akidah Aswaja dan terbentuknya karakter yang mencintai tanah air. Hal ini dikuatkan oleh Alifatul Azizah dkk yang mengatakan bahwa membiasakan peserta didik dengan menguatkan nilai religius seperti memulai hari dengan pembacaan Asmaul Husna bersama-sama dapat menanamkan karakter religius dan nasionalisme pada diri siswa sejak dini. ${ }^{28}$

Dari pemaparan di atas dapat diketahui bahwa pembiasaan tradisi yang dilakukan melalui ziarah Walisanga dan pembacaan Asmaul Husna dapat menguatkan akidah Aswaja dalam diri siswa. Pembiasaan tradisi tersebut bentuk upaya yang dilakukan oleh Yayasan Al-Mahrusiyah dalam menangkal faham radikalisme dalam pendidikan. Dengan akidah Aswaja yang kuat, akhirnya melahirkan perilaku atau sikap yang mencerminkan faham Aswaja. Sikap atau perilaku tersebut akan menjadikan siswa sebagai Islam moderat yang berasas Aswaja, sehingga faham-faham lain akan sulit memengaruhinya. Sebagaimana gambar 1 berikut ini.

\footnotetext{
${ }^{26}$ Idammatussilmi, "Pencegahan Radikalisme melalui Pembiasaan Tradisi Islam Nusantara di MI Najmul Huda Kemloko Temanggung," Citra Ilmu, Vol 17, No. 28, (2018), 39.

${ }^{27}$ Mulyawan Safwandy Nugraha dan Ai Rohayani, "Strategi Guru Aqidah Akhlak dalam Penanggulangan Potensi Radikalisme di MAN 1 Kota Sukabumi," Jurnal Diklat Keagamaan, Vol. 13, No. 2, (2019), 235.

${ }^{28}$ Alifatul Azizah Istiyani, Ahmad Shofiyuddin Ichsan, dan Samsudin, "Pembelajaran Aswaja sebagai Basis Kekuatan Pendidikan Karakter Cinta Tanah Air di MI Ma'arif Sambeng Bantul Yogyakarta,” Tarbiya Islamia: Jurnal Pendidikan dan Keislaman, Vol. 11, No. 1, (2021), 41.
} 


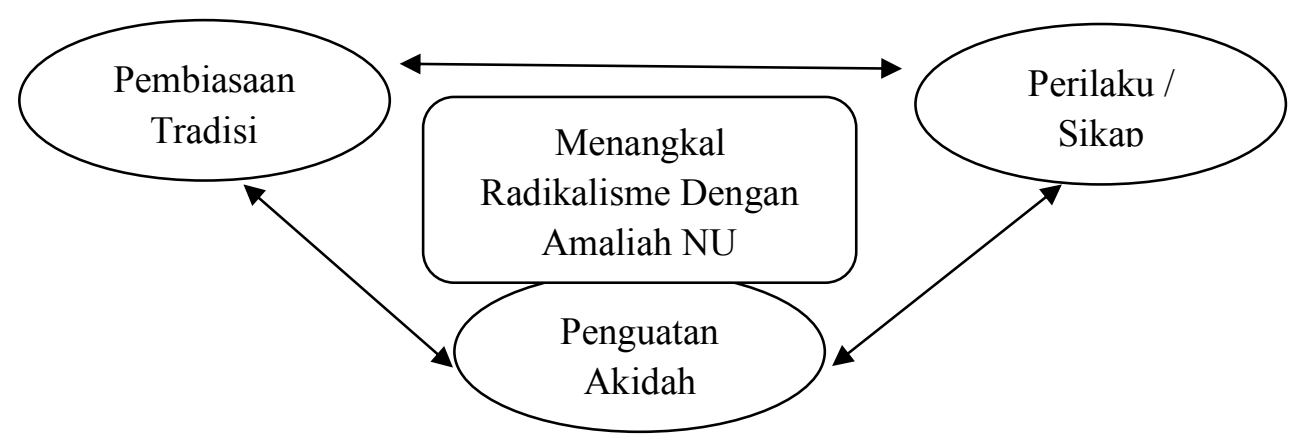

\section{Gambar 1. Skema Menangkal Radikalisme Melalui Amaliah NU}

Skema tersebut menjelaskan tentang siklus amaliah NU dalam menangkal faham radikalisme. Pertama yakni melalui pembiasaan tradisi. Dalam pembiasaan tradisi ini dilakukan dengan penerapan amaliah NU dalam kesehariannya. Kedua, setelah ada pembiasaan, maka akan muncul penguatan akidah Aswaja dalam diri siswa. Penguatan akidah ini memicu siswa akan terbentengnya faham Aswaja dari faham radikalisme. Ketiga, ketika akidah Aswaja kuat, maka muncul sikap atau perilaku siswa mengenai nilai-nilai yang sesuai dengan karakter Aswaja. Siklus tersebut akan terus berlanjut selama amaliah NU diterapkan. Sehingga siswa tidak akan terpengaruh dengan adanya faham radikalisme.

Hal ini bertentangan dengan konsep pendidikan karakter. Upaya Pendidikan karakter dalam menanamkan warga sekolah supaya berperilaku seperti nilai-nilai tertentu yakni melalui proses knowing, feeling, dan doing. ${ }^{29}$ Pertama, proses knowing dilakukan dengan pemberian materi atau pengarahan kepada siswa mengenai nilai-nilai karakter, dengan begitu pengetahuan tentang kebaikan akan terbentuk dalam diri siswa. Kedua proses feeling, apabila pengetahuan tentang kebaikan terbentuk dalam diri siswa, maka keinginan untuk berbuat kebaikan tersebut terlintas dalam pikiran siswa. Ketiga proses doing, yakni ketika siswa sudah memiliki keinginan untuk berbuat kebaikan, maka siswa akan melakukan perbuatan kebaikan tersebut. ${ }^{30}$

Dari penjelasan di atas, proses pembiasaan amaliah NU dalam menangkal faham radikalisme dengan proses pembentukan karakter sebenarnya hampir sama. Hanya saja proses demi proses yang dilakukan keduanya berbeda. Dalam pembiasaan amaliah NU yang pertama yakni proses doing melalui membiasakan tradisi atau amaliah NU. Setelah membiasakan dengan amaliah NU, siswa akan mendapat penguatan akidah Aswaja dengan

\footnotetext{
29 Zaenal Arifin dan Moh. Turmudi, "Character Of Education in Pesantren Perspevtive: Study of Various Methods of Educational Character at Pesantren in Indonesia," Tribakti: Jurnal Pemikiran Keislaman, Vo. 30, No. 2 (Juli 2019), 339.

30 Muzhoffar Akhwan, "Pendidikan Karakter: Konsep dan Implementasinya dalam Pembelajaran di Sekolah/Madrasah," El-Tarbawi, Vol. 7, No. 1 (2014), 62.
} 
melalui proses knowing. Kemudian yang terakhir siswa akan feeling dan juga doing melalui memunculkan perilaku atau sikap yang diperoleh dari pembiasaan tersebut. Perilaku atau sikap yang dimunculkan siswa setelah melakukan pembiasaan tradisi amaliah NU yakni mereka akan lebih tenang dalam bertutur kata, sopan, dan mengedepankan nilai-nilai Aswaja. Hal ini sejalan dengan hasil penelitian Zaenal Arifin dan Moh. Turmudi yang menyatakan bahwa proses pembentukan karakter di pesantren dimulai dengan proses doing (melakukan). ${ }^{31}$ Di mana proses ini berbeda dengan konsep hirarki pembentukan karakter pada umumnya, yaitu knowing, feeling, dan doing. ${ }^{32}$

\section{Penutup}

Berdasarkan pembahasan, peneliti menyimpulkan bahwa: Pertama, pelaksanaan amaliah NU di MAAMLK terdapat dua kegiatan, yakni ziarah Walisanga dan pembacaan Asmaul Husna. Ziarah Walisanga dilaksanakan setiap setahun sekali dan diikuti oleh siswa siswi kelas XII. Ziarah Walisanga dilakukan dengan mengunjungi beberapa makam waliyullah dan ulama-ulama yang berada di tanah Jawa. Pembacaan Asmaul Husna dilakukan oleh seluruh siswa siswi MAAMLK setiap hari di waktu pagi sebelum pembelajaran dimulai. Pembacaan Asmaul Husna dipimpin oleh perwakilan siswa dan dibaca setelah pembacaan Sab'ul Munjiyat dan juga tawasul. Kedua, bentuk revitalisasi amaliah NU dalam menangkal radikalisme yakni dengan pembiasaan ziarah Walisanga dan pembacaan Asmaul Husna. Dengan pembiasaan amaliah NU tersebut siswa akan memperoleh penguatan akidah Aswaja. Hal tersebut akan memunculkan sikap atau perilaku siswa yang sesuai dengan faham Aswaja, dan tentunya sikap tersebut dapat menangkal faham radikalisme

\section{Daftar Rujukan}

Akhwan, Muzhoffar. "Pendidikan Karakter: Konsep dan Implementasinya dalam Pembelajaran Di Sekolah/Madrasah.” El-Tarbawi Vol. 7, no. 1 (2014): 61-67.

Amir, Hasan Baharun, and Lina Nur Aini. "Penguatan Pendidikan Aswaja An-Nahdliyah untuk Memperkokoh Sikap Toleransi." Jurnal Islam Nusantara Vol. 04, no. 02 (2020): 189-202.

\footnotetext{
31 Arifin and Turmudi, "Character Of Education in Pesantren Perspevtive: Study Of Various Methods of Educational Character at Pesantren in Indonesia."

32 Thomas Lickona, Educating for Character: How Our School Can Teach Respect and Responsibility (New York, Toronto, London, Sydney, Aucland: Bantam books, 1991).
} 
Arifin, Zaenal, and Moh. Turmudi. "Character of Education in Pesantren Perspevtive: Study Of Various Methods of Educational Character at Pesantren in Indonesia." Tribakti: Jurnal Pemikiran Keislaman Vo. 30, no. 2 (July 2019): 335-48.

Ariyati, Sri, and Titik Misriati. "Perencanaan Animasi Interaktif Pembelajaran Asmaul Husna." Jurnal Teknik Komputer Amik BSI Vol. 2, no. 1 (2016): 116-21.

Azizah Istiyani, Alifatul, Ahmad Shofiyuddin Ichsan, and Samsudin. "Pembelajaran Aswaja sebagai Basis Kekuatan Pendidikan Karakter Cinta Tanah Air di MI Ma'arif Sambeng Bantul Yogyakarta." Tarbiya Islamia: Jurnal Pendidikan Dan Keislaman Vol. 11, no. 1 (2021): 36-53.

dkk, Hardani. Metode Penelitian Kuantitatif \& Kualitatif. 1st ed. Yogyakarta: CV. Pustaka Ilmu Group Yogyakarat, n.d.

Fauzi, Ahmad. "Jam'iyah Yasin sebagai Media Penyebaran Islam Moderat pada Masyarakat." Proceeding: The 1st Faqih Asy'ari Islamic Institute International Conference Faqih Asy'ari Islamic Institute Sumbersari Kediri, Indonesia Vol. 2 (2019): 104-16.

Haris Masyrufi, Abdul, and Oksiana Jatiningsih. "Partisipasi Remaja Masjid dalam Mencegah Penyebaran Radikalisme Islam di Desa Mojopurogede Kecamatan Bungah Kabupaten Gresik." Kajian Moral dan Kewarganegaraan Vol.5, no. 1 (2017): 507-21.

Idammatussilmi. "Pencegahan Radikalisme melalui Pembiasaan Tradisi Islam Nusantara di MI Najmul Huda Kemloko Temanggung." Citra Ilmu Vol 17, no. 28 (2018): 29-40.

Kemdikbud. "Kamus Besar Bahasa Indonesia (KBBI) Daring," 2021. https://kbbi.kemdikbud.go.id/entri/radikalisme.

Khoirunnisa, Lili. "Hubungan antara Kebiasaan Membaca Asmaul Husna dengan Kecerdasan Emosional Siswa Kelas XI MA Nurul Ummah Yogyakarta.” Jurnal Pendidikan Agama Islam Vol. 14, no. 1 (2017): 51-68.

Lickona, Thomas. Educating for Character: How Our School Can Teach Respect and Responsibility. New York, Toronto, London, Sydney, Aucland: Bantam books, 1991.

Masduqi, Irwan. "Deradikalisasi Pendidikan Islam Berbasis Khazanah Pesantren." Jurnal Pendidikan Islam Vol. 2, no. 1 (2013): 1-20.

Mukodi, Mukodi. "Kurikulum dan Pendidikan Nasionalisme di Pondok Pesantren Tremas." Al Izzah: Jurnal Hasil Penelitian Vol. 15, no. 1 (2020): 14-27.

Mustaghfiroh, Hikmatul, and Muhammad Mustaqim. "Analisis Spiritualitas Para Pencari Berkah (Studi Atas Motivasi Penziarah di Makam Sunan Kalijaga Kadilangu Demak)." Jurnal Penelitian Vol. 8, no. 1 (2014): 143-60.

Rohman, Fathur, and Hanifa A'la. "Pembiasaan Tradisi Aswaja sebagai Upaya Pencegahan Radikalisme di Madrasah Aliyah Matholi'ul Huda Kedung Jepara." El-Banat Jurnal Pendidikan Islam Vol. 10, no. 1 (2020): 128-48.

Rosada, and Wawansyah. "Tradisi Ziarah Kubur Masyarakat Sasak (Studi Kasus Makam Loang Baloq).” Jurnal Historis Vol. 2, no. 1 (2017): 32-38.

Safwandy Nugraha, Mulyawan, and Ai Rohayani. "Strategi Guru Akidah Akhlak dalam Penanggulangan Potensi Radikalisme di MAN 1 Kota Sukabumi." Jurnal Diklat Keagamaan Vol. 13, no. 2 (2019): 230-40. 
Sugiyono. Metode Penelitian Kuantitatif, Kualitatif, dan R\&D. Bandung: Alfabeta, 2012.

Sultoni, Maskuri, and Fita Mustafida. "Peran Guru Pendidikan Agama Islam dalam Menanamkan Amaliyah Ahlussunah Wal Jama'ah Siswa di SMP Nahdlatul Ulama Pakis Malang." Vicratina: Jurnal Pendidikan Islam Vol. 6, no. 1 (2021).

Syahputra, Muhammad Candra. "Jihad Santri Mellenial Melawan Radikalisme di Era Digital: Studi Gerakan Arus Informasi Santri Nusantara di Media Sosial." Jurnal Islam Nusantara Vol. 04, no. 01 (2021): 69-80.

Ummul Fithriyah, Mustiqowati, and M. Saiful Umam. "Internalisasi Nilai-Nilai Aswaja dalam Pendidikan Islam sebagai Upaya Deradikalisasi Menuju Good Citizen." Seminar Nasional Islam Moderat, 2018, 110-24.

Warisno, Andi. “Tradisi Tahlilan Upaya Menyambung Silaturahmi.” Ri'ayah Vol. 2, no. 2 (2017): 69-79.

Washoli, Imam. Sejarah MA Al-Mahrusiyah Lirboyo Kota Kediri. Wawancara, June 15, 2021.

Yani, Ahmad, and Jazariyah. "Penyelenggaraan PAUD Berbasis Karakter Kebhinekaan sebagai Upaya Pencegahan Radikalisme Sejak Dini." Jurnal Obsesi: Jurnal Pendidikan Anak Usia Dini Vol. 5, no. 1 (2021): 1-13.

Yunus, A Faiz. "Radikalisme, Liberalisme, dan Terorisme: Pengaruhnya terhadap Agama Islam.” Jurnal Studi Al-Qur'an Vol. 13, no. 1 (2017): 76-94.

Zahra, Fatimatuz. "Tradisi Aswaja dalam Prespektif Filsafat Terapan." Seminar Nasional Islam Moderat, 2018, 42-54. 